\title{
GESTÃO PARTICIPATIVA DE POLÍTICAS URBANAS: ATUAÇÃO DO CAJU NA REGULAMENTAÇÃO DAS ZEIS EM FORTALEZA
}

OLIVEIRA, B.S. ${ }^{1}$; RIBEIRO, D. F. ${ }^{2} \&$ PEREIRA, M. F. R. ${ }^{3}$

${ }^{1}$ Graduado em Direito pela Universidade Federal do Ceará (UFC). Membro do Centro de Assessoria Jurídica Universitária (CAJU) entre 2016 e 2018. E-mail: bdesousaoliveira@ @mail.com; ${ }^{2}$ Graduanda em Direito pela Universidade Federal do Ceará (UFC). Membro do Centro de Assessoria Jurídica Universitária (CAJU) entre 2016 e 2018. E-mail: davila.ribeiro10@ gmail.com; ${ }^{3}$ Professor da Universidade Federal do Ceará (UFC). E-mail: marciofrpereira@gmail.com.

\section{RESUMO}

DOI: https://doi.org/10.32356/exta.v2.n18.33570 - Artigo submetido em 02/09/2018

As Zonas Especiais de Interesse Social (ZEIS) foram introduzidas, em Fortaleza, pelo Plano Diretor Participativo de 2009. Apesar de passados aproximadamente 10 anos, as ZEIS ainda não foram efetivadas. Nesse contexto, o presente trabalho visa discorrer sobre a atuação do Centro de Assessoria Jurídica Universitária (CAJU) no processo de implementação das ZEIS na cidade e de eleição de seus Conselhos Gestores, que se iniciou no segundo semestre de 2018. Enquanto instrumento que busca garantir o cumprimento da função social da propriedade e a gestão democrática da cidade, as ZEIS necessitam de Conselhos Gestores, instâncias de natureza consultiva e deliberativa que visam a democratização, a publicização e o acompanhamento, por parte da comunidade, dos processos decisórios e ações voltadas a seus territórios. O acompanhamento das ZEIS e da criação de seus Conselhos Gestores, pelo CAJU, enquanto Assessoria Jurídica Universitária Popular (AJUP), tem se dado a partir da defesa de que as comunidades devem ser protagonistas das lutas pela efetivação das políticas públicas; cabendo aos estudantes fortalecer tais sujeitos, funcionando como um canal de diálogo entre comunidade e poder público e atuando para que o entendimento acerca dos normativos da política urbana e sua importância prática esteja acessível às comunidades. O objetivo do presente trabalho, portanto, é apresentar como ocorreu a atuação do CAJU, enquanto Extensão Universitária, no processo de implementação das ZEIS em Fortaleza. Para isso, o presente trabalho utilizou como metodologia a análise documental, sobretudo de atas de reuniões e encontros em que o CAJU esteve presente, e revisão bibliográfica.

PALAVRAS-CHAVE: Política Urbana. Participação Popular. ZEIS. CAJU. Assistência de Enfermagem.

\section{PARTICIPATIVE MANAGEMENT OF URBAN POLICIES: MONITORING BY CAJU OF ZEIS REGULATION IN FORTALEZA}

\section{ABSTRACT}

The Special Areas of Social Interest (ZEIS) were introduced in Fortaleza by the Participative Master Plan of 2009. Although approximately 10 years have passed, the ZEIS have not been implemented yet. In this context, this paper aims to discuss the work of the University Legal Advisory Center (CAJU) in the process of implementing the ZEIS in the city and the election of its Managing Councils, which began in the second half of 2018. As an instrument that seeks to ensure the fulfillment of the social function of the property and the democratic management of the city, the ZEIS need Management Councils, advisory and deliberative bodies that aim at the democratization, publicity and monitoring by the community of the decision-making processes and actions in their territories. The monitoring of the ZEIS and the creation of its Managing Councils by the CAJU, as a
University Legal Advisory Committee for the Popular (AJUP), has been based on the defense that communities must be protagonists of the struggles for the implementation of public policies. It is up to the students to strengthen these subjects, functioning as a channel of dialogue between community and public power and acting to the understanding about the norms of urban politics and its practical importance be accessible to the communities. The objective of this work, therefore, is to present how the CAJU monitoring occurred, as a university extension, in the implementation of ZEIS in Fortaleza. For this, the present work used as methodology the documentary analysis, in particular minutes of meetings in which CAJU was present, also literature review.

KEYWORDS: Urban Policy. Popular Participation. ZEIS. CAJU. 


\section{INTRODUÇÃO}

A Extensão é um dos aspectos integrantes do que se denomina tripé universitário, cumprindo tanto o papel de aproximar a Universidade da Sociedade como o de complementar a formação do estudante, juntamente com o ensino e a pesquisa. No presente trabalho irá ser analisada a atuação do projeto "Acompanhamento e Controle Social da Política Urbana de Fortaleza", integrante do Programa Centro de Assessoria Jurídica Universitária (CAJU).

O CAJU se caracteriza por sua prática enquanto Extensão Popular, intimamente ligada à atuação das chamadas Assessorias Jurídicas Universitárias Populares (AJUPs), e desenvolve seus projetos segundo esse modelo. Nesse método de Extensão, além da proximidade com os setores sociais historicamente marginalizados, busca-se, através da prática da Educação Popular, cujo marco teórico está em Paulo Freire, realizar ações que possibilitem o fortalecimento e o protagonismo das comunidades envolvidas, além da efetivação de direitos básicos.

Com isso, o projeto "Acompanhamento e Controle Social da Política Urbana de Fortaleza" vem, nos últimos anos e especialmente em 2018, como será demonstrado adiante, participando das discussões acerca da regulamentação das Zonas Especiais de Interesse Social (ZEIS) na cidade.

Para isso, o CAJU se coloca ao lado das comunidades que, sendo ZEIS, são caracterizadas como prioritárias para o investimento das políticas urbanas; nesse sentido, participando, por exemplo, de diversos debates junto ao Poder Público para pressionar a efetivação desse importante instrumento de justiça social e de garantia do direito à cidade e à moradia. Além disso, o núcleo se articula dentro da Frente de Luta por Moradia Digna, organização formada por comunidades, movimentos organizados, ONGs e entidades de assessoria técnica que busca construir ações que visibilizem a grandiosidade do problema da falta de moradia digna em Fortaleza e da dificuldade de acesso ao Direito à Cidade. Por fim, são feitas ações de extensão dentro desses territórios, como tem ocorrido no Lagamar, a fim de empoderar os moradores, através da prática da Educação Popular, com o conhecimento dos direitos que ser ZEIS lhes assegura.

Para elaboração do presente artigo, foi feito estudo de dois principais instrumentos da legislação urbana: o Estatuto da Cidade e o Plano Diretor Participativo de Fortaleza, ambos examinados à luz da Constituição Federal de 1988. Além disso, houve a análise de decretos municipais e de relatórios feitos pelo Poder Público municipal no que tange à regulação das 
ZEIS. Os relatos históricos aqui descritos foram feitos, por sua vez, a partir do resgate de atas de reuniões tanto da Frente de Luta por Moradia Digna como do próprio CAJU, além de notícias veiculadas à época dos fatos explorados no presente artigo. Não se pode deixar de mencionar, ainda, a leitura de bibliografia especializada acerca dos instrumentos urbanísticos e jurídicos discutidos neste trabalho.

\section{DEMOCRACIA PARTICIPATIVA E GESTÃO DA CIDADE}

O processo de urbanização das cidades brasileiras, intensificado sobretudo a partir de década de 70 (SANTOS, 1993), teve impacto direto na desigualdade de acesso a direitos básicos por grande parcela da população. As marcas de um planejamento urbano excludente estão presentes no cotidiano das populações, sobremaneira nos grandes centros urbanos. Em Fortaleza, para apontarmos o lócus de atuação do CAJU, mais de $30 \%$ da população vive em assentamentos precários (FORTALEZA, 2015).

Durante parcela do século XX, em especial durante o período de Ditadura Militar, os processos de discussão dos rumos da cidade e, portanto, da resolução dos seus principais problemas, tiveram como norte um processo de planejamento urbano baseado na técnica e realizado exclusivamente por profissionais (VILLAÇA, 1999). A maior parte da população, desse modo, não estava inserida nos processos de planejamento, o que representava, dentre outras coisas, a exclusão no âmbito dos documentos oficiais dos próprios problemas vivenciados, como a questão do acesso à moradia (MARICATO, 2015).

O processo de redemocratização do país marcou a possibilidade do surgimento de cidades menos desiguais e da retomada da participação popular na tomada de decisões. Reflexo disso foi a apresentação de Proposta de Emenda à Constituição pelo Movimento Nacional de Reforma Urbana (MNRU), a qual direcionava-se prioritariamente pela criação de instrumentos que impactassem de forma direta problemas de acesso à terra, de saneamento, de transporte, dentre outros (SILVA, 1991).

Apesar disso, estabeleceu-se na Constituição Federal a necessidade de criação de um instrumento de Planejamento Urbano, o Plano Diretor ${ }^{1}$, prévio à aplicação de algumas das medidas propostas pelos movimentos populares. Com o advento da Lei $\mathrm{n}^{\mathrm{o}} 10.257 / 01^{2}$, estava

\footnotetext{
${ }^{1}$ Art. 182. A política de desenvolvimento urbano, executada pelo Poder Público municipal, conforme diretrizes gerais fixadas em lei, tem por objetivo ordenar o pleno desenvolvimento das funções sociais da cidade e garantir o bem- estar de seus habitantes. $\S 1^{\circ} \mathrm{O}$ plano diretor, aprovado pela Câmara Municipal, obrigatório para cidades com mais de vinte mil habitantes, é o instrumento básico da política de desenvolvimento e de expansão urbana.

${ }^{2}$ Art. $2^{\circ}$ A política urbana tem por objetivo ordenar o pleno desenvolvimento das funções sociais da cidade e da propriedade urbana, mediante as seguintes diretrizes gerais: II - gestão democrática por meio da participação da população e de associações representativas dos vários
} 
estabelecido normativamente que os Processos de Planejamento Urbano deveriam ser participativos.

Nesse sentido, passou-se a entender que todo o gerenciamento da cidade deve, no que tange ao desenvolvimento social urbano, passar obrigatoriamente por um processo de amplo debate público. A respeito disso, Lígia Maria Silva Melo de Casimiro ressalta a importância das deliberações democráticas, a partir da análise de que as políticas urbanas têm por destinatário específico a população do território onde vão se desenvolver tais projetos (CASIMIRO, 2017).

Os princípios estabelecidos no Estatuto da Cidade $^{3}$ objetivaram aprimorar a ideia da democracia urbana, buscando "a construção coletiva da cidade, por meio de um processo que retira da própria constituição seu fundamento, legitimando as decisões administrativas que levam em conta a pluralidade conflituosa de interesses" (CASIMIRO, 2017).

Tem-se, conforme observam Telmo Filho e Carla Vasconcellos, que a evolução da ideia de democracia trouxe um modelo de planejamento urbano misto, pois propõe-se, ao mesmo tempo, a ser deliberativo (através dos espaços de debate, como conselhos e audiências) e participativo, mais emancipatório e inclusivo (através da participação direta e controle popular dos processos) (FILHO; VASCONCELLOS, 2011).

Entretanto, vários são os desafios que se colocam na efetivação dos mecanismos de participação popular no Brasil, a começar pela predominância da lógica dos processos políticos de representação (RICCI, 2002, p. 96), representada pela ausência da garantia de condições mínimas de participação da população, como a disponibilidade de informações básica e a adequação dos espaços de discussão às limitações de ordem socioeconômica dos que desejam participar (CASIMIRO, 2017).

Assim, a discussão sobre a atuação do CAJU no processo de implementação das ZEIS no Município de Fortaleza tem o objetivo de apresentar a correlação entre a prática da Assessoria Jurídica Universitária e a busca pela efetivação da gestão democrática das cidades, localizando tal prática enquanto Extensão Universitária.

segmentos da comunidade na formulação, execução e acompanhamento de planos, programas e projetos de desenvolvimento urbano; 3 Art. 43. Para garantir a gestão democrática da cidade, deverão ser utilizados, entre outros, os seguintes instrumentos: I - órgãos colegiados de política urbana, nos níveis nacional, estadual e municipal; II - debates, audiências e consultas públicas; III - conferências sobre assuntos de interesse urbano, nos níveis nacional, estadual e municipal; IV - iniciativa popular de projeto de lei e de planos, programas e projetos de desenvolvimento urbano; 


\title{
3 AJUP, EXTENSÃO E DIREITO À MORADIA
}

Antes de tratar especificamente da atuação do CAJU na implementação das ZEIS, cumpre mencionar brevemente alguns dos marcos teóricos e práticos relacionados à prática da Assessoria Jurídica Universitária Popular (AJUP). A prática da AJUP tem como uma de suas características a busca pelo rompimento com a perspectiva de assistência jurídica, como bem aponta Ana Lia Almeida:

\begin{abstract}
A perspectiva da assistência jurídica, simbolizada pelo atendimento técnico-jurídico a casos individuais, passa a ser avaliada como insuficiente e inadequada para intervir nas reais causas dos conflitos sociais, pois reforçava o universo simbólico dominante no direito (com sua linguagem difícil, seus tribunais opulentos etc.). Havia, ademais, uma forte influência de perspectiva que, no contexto de redemocratização do país, contribuíram para os processos de mobilização da classe trabalhadora e dos demais sujeitos subalternizados, a exemplo das reflexões de Paulo Freire (2015, p.78, grifos da autora)
\end{abstract}

Essa perspectiva assistencialista, a qual permeia o próprio surgimento da Extensão Universitária no Brasil (FORPROEX, 2012), se pauta na imposição unilateral de conceitos e conhecimentos acadêmicos, desconsiderando o contexto social dos sujeitos com os quais a relação se estabelece.

Nesse sentido, a busca por intervenções no que se aponta como causas reais dos conflitos sociais parte da ideia de que apesar de o Estado afirmar que os direitos estão essencialmente contidos nas leis (LYRA FILHO, 1993, p.33), a aplicação ou não das leis guarda relação direta com as forças sociais dominantes (MASCARO, 2013).

A prática da AJUP, desse modo, se propõe a ser um instrumento de emancipação de sujeitos historicamente vulnerabilizados, através da educação popular, da democratização e do intercâmbio de saberes. A AJUP, fazendo a opção político-ideológica de fortalecer a luta dos movimentos sociais e compreendendo a extensão como um caminho essencial que liga a Universidade aos saberes populares, possui como um de seus referenciais teóricos Paulo Freire e sua Educação Popular.

A educação popular se traduz justamente na perspectiva dialógica e de valorização dos inúmeros conhecimentos populares. Fundamentado nas ideias de Paulo Freire, esse princípio busca ir contra o modelo de ensino-aprendizagem tradicional, no qual um polo é apresentado como detentor do conhecimento e o outro como mero espectador (FREIRE, 1987, p.39). Na prática da AJUP, o que se procura é dar autonomia aos sujeitos assessorados, transmitindo e democratizando o conhecimento universitário, mas antes, valorizando e apreendendo saberes da comunidade. É inerente a essa ideia, portanto, a compreensão da educação transformadora. 
Nesse sentido, importa mencionar brevemente algumas premissas de atuação no tema do Direito à Cidade sob uma perspectiva da Educação Popular apresentada. Se, como explanado anteriormente, a participação popular no planejamento das cidades só foi alçada a norma com o advento da Constituição Federal de 1988, isso não significa que o Direito à Cidade se confunde com tal advento.

O reconhecimento de que as reivindicações dos segmentos populares, das quais o acesso à moradia é um exemplo, podem não coincidir com a legalidade vigente é essencial na atuação sob a perspectiva da Educação Popular, aproximando-se do que denomina como Pluralismo Jurídico (LYRA FILHO, 1993, p.33). Nesse sentido “o que caracteriza a ação destes movimentos, sua eficiência e capacidade de articulação de soluções é a convicção de que a sua ação encontra apoio num direito que não coincide necessariamente com a legalidade oficial vigente" (LYRA FILHO, 1993, p.35)

Como parte dessa articulação, a atuação da AJUP pode ou não ser conflitante com a chamada legalidade oficial. Isto porque muitas vezes as reivindicações populares passam a configurar a própria legalidade oficial, como é o caso das ZEIS apresentado no presente trabalho. Nesses casos, o que tem que ser observado é se há "a instrumentalização pró-estatal da ineficiência do próprio direito estatal" (FALCÃO, 1993, p. 112), ou seja, se o Estado está ou não aplicando os direitos previstos.

Assim, o intercâmbio de saberes e práticas propiciados pela Educação Popular contribui tanto para o reconhecimento, por parte de quem atua na perspectiva da AJUP, de direitos que não estão previstos legalmente, como possibilita o acompanhamento dos processos de reconhecimento legal desses direitos (FALCÃO, 1993 p. 111). Desse modo, será apresentado em seguida como o CAJU atuou no processo de acompanhamento da implementação das ZEIS no Município de Fortaleza.

\section{ZEIS: ATUAÇÃO DO CAJU NA CONCRETIZAÇÃO DOS INSTRUMENTOS LEGAIS URBANOS EM FORTALEZA}

As Zonas Especiais de Interesse Social (ZEIS) foram introduzidas, no município de Fortaleza, pelo Plano Diretor Participativo de 2009 (Lei Complementar no 62/2009), com a seguinte redação:

Art. 123 - As Zonas Especiais de Interesse Social (ZEIS) são porções do território, de propriedade pública ou privada, destinadas prioritariamente à promoção da regularização urbanística e fundiária dos assentamentos habitacionais de baixa renda existentes e consolidados e ao desenvolvimento de programas habitacionais de 
interesse social e de mercado popular nas áreas não edificadas, não utilizadas ou subutilizadas, estando sujeitas a critérios especiais de edificação, parcelamento, uso e ocupação do solo. (PDFor, 2009)

Ao delimitar esse Zoneamento Especial, a legislação urbanística municipal estabelece áreas do território que exigem tratamento especial na definição de parâmetros reguladores de usos e ocupação do solo, buscando adequá-los à realidade socioambiental da população, majoritariamente de baixa renda, que vive nessas zonas.

Como afirma Marcelo Lopes de Souza, as ZEIS representam um dispositivo ímpar a partir do qual se pode possibilitar a inversão de prioridades, passando a adotar como alvo da política urbana aqueles setores que reúnam como características: irregularidade fundiária, precariedade das infraestruturas, desordem urbanística, condição de pobreza e densidade excessiva (SOUZA, 2001).

Nesse sentido, as ZEIS se mostram um importante instrumento jurídico-político para a efetivação do interesse público, através de medidas que visam garantir o direito à moradia, por meio da regularização fundiária, por exemplo, e à cidade, visando ampliar a oferta de infraestrutura e equipamentos comunitários, bem como são uma ferramenta fundamental para gestão democrática de políticas urbanas, garantindo à população espaço para debater e interferir nos projetos e programas urbanos que ocorram em seus territórios.

O Plano Diretor Participativo de Fortaleza (PDFor), por sua vez, definiu das ZEIS de modo genérico, em geral reproduzindo os normativos do Estatuto da Cidade, de modo que a efetiva regulamentação do funcionamento dessas Zonas ficou reservada a legislações específicas, a sersem criadas posteriormente.

Vale destacar que cidades como Recife e Belo Horizonte desde a década de 1980 já buscavam inserir em seu ordenamento áreas de assentamentos informais com intuito de destinar, para elas, investimentos especiais para urbanização e regularização, mostrando preocupação em controlar o crescimento desordenado, que marginaliza as populações periféricas (ROLNIK; SANTORO, 2014). Por exemplo, em 2005, 66 localidades haviam sido formalmente reconhecidas como ZEIS em Recife, ocupando $12 \%$ da área do município (MORAES, 2005). Assim, contrastando Fortaleza com essas cidades, fica claro o atraso da capital cearense para promover a regulação de suas regiões mais precárias, demonstrando o desinteresse das gestões públicas em promover um desenvolvimento urbano mais igualitário no do município.

Com isso, é preciso ressaltar que a inclusão das ZEIS no mapeamento de Fortaleza foi 
resultado não da benevolência do legislativo municipal à época, envolvido na formulação do PDPFor, mas sim de uma série de pressões populares ao longo de seu processo de elaboração, por meio da participação de diversas lideranças comunitárias articuladas nas audiências públicas setoriais para elaboração participativa do Plano Diretor (PEQUENO; FREITAS, 2011). Sendo as ZEIS, com isso, um primeiro, porém tardio reconhecimento de uma série de lutas das comunidades e movimentos sociais pelo direito à cidade e à função social da propriedade.

Assim, este tópico do trabalho se voltará a analisar os processos que envolvem as lutas travadas em busca da regulamentação desse importante instrumento, em especial das ZEIS tipo 1, definidas no Plano Diretor como áreas compostas por assentamentos de ocupação desordenada, precários do ponto de vista urbanístico e habitacional, formados por população de baixa renda, pois é principalmente junto às comunidades localizadas nessas zonas que estão centradas as ações de extensão desenvolvidas pelo CAJU ao longo dos últimos anos.

Apesar do avanço trazido pela previsão legal das ZEIS, essa conquista foi apenas o início da luta para sua concretização. Precisando, pois, haver uma série de outras movimentações populares, como atos, ocupações, reuniões e audiências públicas, para pressionar o Poder Público Municipal a reconhecer e aplicar esse instrumento.

De início, apesar de intensa mobilização de algumas comunidades, como das ZEIS do Lagamar, do Poço da Draga e do Serviluz, houve poucas vitórias. O que se pôde observar, desde a provação do PDPFor em 2009, é que, apesar do esforço e da pressão da população, não havia vontade política do Poder Público para fornecer recursos para que os instrumentos necessários à efetivação das ZEIS pudessem se estabelecer.

Foi só no primeiro semestre de 2013, devido a uma maior articulação popular, após uma manifestação sob a forma de acampamento em frente à sede da prefeitura, que se conseguiu um acordo para criação do Comitê Técnico Intersetorial e Comunitário para tratar da regulamentação das ZEIS em Fortaleza. Esse Comitê, instituído pelo Decreto n ${ }^{\circ} 13.241$, de 21 de outubro de 2013, seria, então, uma ferramenta de gestão participativa com a finalidade de gerar um relatório contendo informações apuradas para subsidiar uma tomada de decisão, pela prefeitura, quanto às ações prioritárias para a efetiva implantação do zoneamento especial.

O Comitê efetivamente iniciou seus trabalhos em 14 de abril de 2014, numa reunião convocada pelo Instituto de Planejamento de Fortaleza (IPLANFOR), órgão municipal responsável por coordenar os processos de regulamentação das ZEIS, e era composto por 
representantes de vários órgãos do poder municipal, de moradores das ZEIS prioritárias e de representantes das universidades, que se dispuseram a assessorar as comunidades, de modo a auxiliá-las, por exemplo, com o linguajar técnico das discussões.

Apesar das dificuldades com a disponibilidade de horários, alguns membros do CAJU conseguiram acompanhar as reuniões desse comitê a partir de junho de 2015, garantindo apropriação das discussões que lá ocorriam pelo restante dos membros que compunham o núcleo de extensão através do o constante compartilhamento nas reuniões ordinárias do projeto (BARBOSA, VIEIRA, 2018). Foi principalmente a partir dessa atuação no Comitê que o CAJU se aproximou das comunidades e pautas de lutas das ZEIS.

O relatório final deste processo foi entregue em 26 de outubro de 2015. Ao final, o documento propunha, entre outras medidas, a criação de uma Comissão de Proposição e Acompanhamento da Regulamentação das ZEIS, de caráter temporário, para, dentre outras atribuições, elaborar a proposta de lei que finalmente regulamentaria as Zonas Especiais de Interesse Social em Fortaleza. Essa comissão foi criada pelo Decreto municipal $\mathrm{n}^{\circ} 13.827 \mathrm{de}$ 14 de junho de 2016 (renovado pelo Decreto 13.954 de 11 de janeiro de 2017).

Fizeram parte dela vários representantes da administração municipal e da sociedade civil, com membros de várias universidades, entre elas a Universidade Federal do Ceará (UFC), do Escritório Frei Tito de Alencar, de organizações populares como a Frente de Luta por Moradia Digna, da qual o CAJU também faz parte, e das dez ZEIS prioritárias - Bom Jardim, Lagamar, Moura Brasil, Mucuripe, Poço da Draga, Pici, Pirambu, Serviluz, Praia do Futuro e Vila Vicentina.

A conclusão dos trabalhos dessa comissão se deu em 23 de setembro de 2017, com a produção de um Relatório Final, que foi entregue ao executivo municipal em 23 de fevereiro de 2018, momento no qual as lideranças comunitárias e representantes das universidades reforçaram ao poder público o caráter participativo do processo de produção das propostas ali registradas e, por isso, a importância de sua integral aplicação.

Esse documento, entre seus resultados, apresentou propostas de leis e de decretos de funcionamento dos Conselhos Gestores das ZEIS, além de propostas de termos de referência para capacitação desses conselhos e para contratação de Plano Integrado de Regularização Fundiária (PIRF) para as ZEIS (FORTALEZA, 2017).

Nesse norte, antes de aprofundarmos o detalhamento das ações do CAJU junto às ZEIS no ano de 2018, faz-se necessário esclarecer que os Conselhos Gestores das ZEIS são instâncias 
de caráter consultivo e deliberativo, constituídos de forma pluralista e equitativa entre os representantes do Poder Público Municipal, dos atuais moradores da comunidades e de entidades da sociedade civil, tendo como objetivo participar da elaboração, implementação e monitoramento dos planos integrados de regularização fundiária - PIRF, na área de sua respectiva ZEIS.

Os PIRFs, por sua vez, consistem em um plano de ação que abrange parâmetros urbanísticos, ambientais, infraestruturais, jurídicos, socioeconômicos, entre outros (FORTALEZA, 2009). Eles têm importância fundamental para as áreas de ZEIS porque orientam os caminhos para a efetivação o direito à moradia da população, a integração dos assentamentos à cidade formal, a inserção da região nos projetos viários da cidade e a inclusão de seus moradores na elaboração e utilização de políticas públicas, projetos habitacionais e ações sociais. É, portanto, por meio dos planos integrados que as ZEIS são regulamentadas e efetivamente alcançam os objetivos para as quais foram criadas.

Assim, uma das principais atribuições do Conselho Gestor consiste em levar ao conhecimento do Poder Público as demandas das comunidades, interferindo no processo de elaboração e implantação dos PIRFs para assegurar o interesse dos moradores, que devem ser os atores principais a guiar esse processo, e monitorar as ações na área.

Percebe-se, portanto, que esses instrumentos são ferramentas essenciais para concretização da gestão democrática da cidade, garantido participação popular na tomada de decisões das políticas de interesse da população, revelando necessária e possível a cooperação para que haja o planejamento racional da cidade. Por isso, têm sido objeto de tanta mobilização social para serem implementados em Fortaleza.

Voltando a analisar a evolução da efetivação desses instrumentos na capital cearense, fazse importante registrar que após a entrega do Relatório Final da Comissão de Proposição e Acompanhamento da Regulamentação das ZEIS, no início de 2018, ocorreram diversos encontros entre as assessorias e as comunidades presentes na Frente de Luta por Moradia Digna junto ao IPLANFOR, para pressionar a gestão municipal a realizar as eleições dos Conselhos Gestores suas atribuições.

Nesse processo, o CAJU não participou diretamente das reuniões com o poder público, principalmente porque os horários nos quais eles ocorriam geralmente chocavam com as aulas dos membros do projeto. Apesar disso, o núcleo sempre se fez presente, auxiliando na construção de estratégias de pressão e cobrança, por meio, por exemplo, da elaboração de uma 
nota online assinada por diversos movimentos populares urbanos. Como resultado dessas articulações, foi publicado, em 22 de maio de 2018, o Decreto ${ }^{\circ} 14.211$ com a previsão da composição dos Conselhos Gestores das ZEIS e de como deveriam ocorrer suas eleições.

Ressalte-se que o referido decreto não respeitou a proposta elaborada pelo pelo Relatório Final da Comissão (2017), uma vez que a composição do conselho estava diferente daquela constante no relatório, pois houve a retirada dos representantes de entidade acadêmica e de movimentos populares, diminuição da presença da comunidade de sete para seis moradores e ampliação da representação do Poder Público, que passou a ser igualitária à da comunidade, além do acréscimo de um representante da Câmara Municipal.

Apesar de tais alterações terem sido mal recebidas pelas comunidades, optou-se por levar adiante o processo de eleições, uma vez que contestar o decreto tomaria mais tempo e, em face de tantos anos de lutas para efetivação das ZEIS, havia urgência em implantá-las.

Assim, no mês de junho de 2018 começou a organização das comissões eleitorais de cada ZEIS, responsáveis por organizar o pleito para os Conselhos Gestores. Uma das atribuições dessas comissões foi justamente produzir um edital que regulasse o processo eleitoral, momento no qual o CAJU contribuiu participando das reuniões de elaboração dos editais, no âmbito da Frente de Luta por Moradia Digna.

Além disso, o CAJU também participou ativamente das mobilizações para realização das eleições na comunidade do Lagamar. Lá, o núcleo esteve presente em diversos momentos do ano de 2018, participando ainda em julho da escolha da comissão eleitoral. Depois, a convite da Fundação Marcos de Bruim, acompanhando as chamadas reuniões de quarteirão, que formavam uma campanha de divulgação das eleições para o Conselhor Gestor dessa ZEIS.

O CAJU foi algumas vezes nos meses de agosto de 2018 ao Lagamar para participar das rodas de discussão organizadas pela Fundação para conversar com os moradores do bairro principalmente sobre os marcos regulatórios das ZEIS, garantias e direitos que esse instrumento poderia trazer para a região. Em síntese, os membros núcleo buscavam tirar dúvidas dos moradores e explicar melhor como se dava o processo de eleição e de que forma os Conselhos Gestores poderiam atuar na resolução dos problemas do bairro, servindo como instrumento de reverberação das demandas da comunidade e de fiscalização da atuação do poder público.

Ademais, uma outra ação do projeto de extensão para contribuir na divulgação das eleições foi a produção de materiais gráficos e panfletos que foram repassadas para as comunidades com auxílio de parceiros da Frente de Luta por Moradia. O material era didático 
e sucinto, buscando explicar a importância da participação popular nesses processos, divulgando também data e horários das votações.

As eleições dos Conselhos Gestores das 10 ZEIS prioritárias ocorreram entre agosto e setembro de 2018, sempre aos finais de semana para possibilitar a participação do maior número possível de moradores (FORTALEZA, 2018a).

Logo após a escolha dos moradores para os conselhos, já em outubro, os representantes das comunidades que participavam da Frente de Luta começaram a se reunir com as assessorias técnicas para organizar as prioridades nos próximos passos de regulamentação das ZEIS. A cerimônia de posse dos eleitos ocorreu no dia 13 de novembro de 2018 e, após essa formalização da constituição dos Conselhos Gestores, os conselheiros passaram por processo de capacitação para iniciarem as atividades (FORTALEZA, 2018b)

O CAJU, por sua vez, continuou participando das reuniões da Frente de Luta por Moradia digna e acompanhando o funcionamento do Conselho Gestor da ZEIS Lagamar, dando prosseguimento às atividades formativas que iniciou no período eleitoral do referido conselho, auxiliando ainda seus membros com a compreensão do regimento interno do Conselho Gestor e interpretação de outros processos burocráticos ligados ao funcionamento dessa instância deliberativa.

\section{CONCLUSÃO}

A partir do exposto neste trabalho, é possível entender melhor a necessidade da participação popular na estruturação das políticas públicas de gestão da cidade, pois ela é essencial para possibilitar uma maior eficiência e legitimidade à atuação do poder público no atendimento das demandas sociais.

Pelo exposto, é notável que existe uma série de desafios à implementação dos diversos instrumentos que permitem a atuação da população junto ao poder público na formulação do planejamento urbano. Ficou claro, ainda, que uma das principais das dificuldades de concretização da democracia participativa é o comprometimento da própria gestão municipal para viabilizar a regulamentação desses mecanismos.

Nesse sentido, o meio mais eficiente de assegurar a efetivação dos dispositivos legais que permitem a inserção social nos debates da política urbana é a mobilização das próprias comunidades implicadas por tais políticas.

Perante tantos desafios e levando em consideração o que foi apresentado sobre o modo 
de articulação e atuação da Assessoria Jurídica Popular, tem-se que a prática extensionista universitária pode ser uma importante aliada nas lutas pela concretização da participação popular na gestão democrática da cidade. Isso porque a atuação das AJUPs, através dos espaços formativos e da Educação Popular, é extremamente relevante no processo de empoderamento das comunidades acerca de seus direitos, permitindo que um número cada vez maior de pessoas passe a dominar a compreensão dos mecanismos legais de inserção popular nas elaboração do planejamento urbano.

Conclui-se, portanto, diante do histórico apresentado, que o CAJU, enquanto um projeto de extensão que se propõe a constituir um modelo de Assessoria Jurídica Popular, tem cooperado de modo relevante na pauta urbana em Fortaleza, principalmente na evolução da regulamentação e na luta pela manutenção das ZEIS como instrumento imprescindível do Plano Diretor para a constituição de uma cidade democrática e inclusiva. Tendo o núcleo, assim, tanto contribuído para diversos dos avanços recentes desse processo quanto crescido do ponto de vista acadêmico e prático em sua atuação dentro e fora da universidade.

\section{REFERÊNCIAS}

ALMEIDA, Ana Lia Vanderlei de. Um estalo nas faculdades de direito: perspectivas ideológicas da Assessoria Jurídica Universitária Popular. 340. f. Tese (Doutorado em Ciências Jurídicas) - Universidade Federal da Paraíba, João pessoa, 2015.

BARBOSA, Guilherme Bezerra; VIEIRA, Larissa Camurça. Assessoria Jurídica Universitária Popular e os processos de tomadas de decisões acerca dos instrumentos de política urbana em âmbito municipal. Braz. Ap. Sci. Rev., Curitiba, v. 2, n. 1, p. 291-304, jan./mar. 2018. Disponível em: http://brazilianjournals.com/index.php/BASR/article/view/380

BRASIL. Decreto n. 14.211, de 21 de maio de 2018. Disciplina as disposições da Lei Complementar $\mathrm{n}^{\circ}$ 062, de 02 de fevereiro de 2009, que instituiu o Plano Diretor Participativo do Município de Fortaleza, relativas à regulamentação dos Conselhos Gestores das Zonas Especiais de Interesse Social - ZEIS 1 e 2, e dá outras providências. Diário Oficial do Município: $n^{\circ}$ 16.264. Fortaleza, p. 1-3. 2018.

BRASIL. Lei Complementar n. 062, de 02 de fev. de 2009. Institui o Plano Diretor Participativo do Município de Fortaleza e dá outras providências. Plano Diretor. Fortaleza.2009. Legislação Complementar. Disponível em: $<$ http://www.planalto.gov.br/ccivil_03/leis/LEIS_2001/L10257.htm>. Acesso em: 30 ago. 2018

BRASIL. Lei n. 10.257, de 10 de jul. de 2001. Regulamenta os arts. 182 e 183 da Constituição Federal, estabelece diretrizes gerais da política urbana e dá outras providências.. Estatuto da Cidade. $\quad$ Brasília. 2001. Legislação Federal. 
Disponível
em: $\langle$ http://legislacao.fortaleza.ce.gov.br/index.php/Plano_Diretor $>$

CASIMIRO, Lígia Maria Silva Melo de. A participação social no planejamento das políticas públicas urbanas. Revista Eurolatinoamericana de Derecho Administrativo, Santa Fe, vol. 4, n. 1, p. XX-XX, ene./jun. 2017. DOI: 10.14409/rr.v4i1.6741.

FALCÃO, Joaquim de Arruda. Justiça Social e Justiça legal: conflitos de propriedade no Recife. In: JUNIOR, José Geraldo de Sousa (org.). Introdução crítica ao direito. 4. Ed. Brasília: Universidade de Brasília, 1993. p.110-121.

FILHO, João Telmo de Oliveira; VASCONCELLOS, Carla Portal. Democracia e participação popular: As possibilidades de transformações nas formas de gestão do território a partir do Estatuto da Cidade. Conferência do Desenvolvimento. II. 2011. Brasília. Área temática: 7. Desenvolvimento e Espaço: ações, escalas e recursos. Anais do I Circuito de Debates Acadêmicos. Disponível em: < http://www.ipea.gov.br/code2011/chamada2011/artigos.html> . Acesso em: 30 ago. 2018.

FORPROEX - FÓRUM DE PRÓ-REITORES DE EXTENSÃO DAS UNIVERSIDADES PÚBLICAS BRASILEIRAS. Plano Nacional de Extensão Universitária. Ilhéus: Editus, 2001. Disponível em: <https://www.ufmg.br/proex/renex/images/documentos/Plano-nacionalde-extensao-universitaria-editado.pdf $>$. Acesso em: 01 abr. 2018

FORTALEZA. Relatório da Comissão de Proposição e Acompanhamento da Regulamentação e Implantação das Zonas Especiais de Interesse Social - Zeis. Prefeitura Municipal de Fortaleza. Fortaleza. 2017

FORTALEZA. Relatório das Zeis. Comitê Técnico Intersetorial e Comunitário das ZEIS. Instituto de Planejamento de Fortaleza (IPLANFOR). Fortaleza. 2015.

FORTALEZA. Prefeitura divulga calendários para eleição do Conselho Gestor de três Zeis. Disponível em: https://www.fortaleza.ce.gov.br/noticias/prefeitura-divulga-calendariospara-eleicao-do-conselho-gestor-de-tres-zeis. Acesso em: 01 set. 2018a.

FORTALEZA. Prefeitura de Fortaleza empossa os membros dos Conselhos Gestores das Zeis. Disponível em: https://www.fortaleza.ce.gov.br/noticias/prefeitura-de-fortalezaempossa-os-membros-dos-conselhos-gestores-das-zeis. Acesso em: 01 set. $2018 \mathrm{~b}$.

FORTALEZA. Prefeito Roberto Cláudio empossa 137 conselheiros das Zeis. Disponível em: https://www.fortaleza.ce.gov.br/noticias/prefeito-roberto-claudio-empossa-137conselheiros-das-zeis. Acesso em: 01 set. 2018b.

FREIRE, Paulo. Pedagogia do Oprimido. 17 a Ed. Rio de Janeiro, Paz e Terra, 1987.

LYRA FILHO, Roberto. Direito e Lei. In: JUNIOR, José Geraldo de Sousa (org.). Introdução crítica ao direito. 4. Ed. Brasília: Universidade de Brasília, 1993. p.31-34.

MASCARO, Alysson Leandro. Estado e forma política. São Paulo: Boitempo, 2013. 
MARICATO, Ermínia. Para entender a crise urbana. São Paulo: Expressão Popular, 2015.

NEVES, Thamira Reis Santana; OLIVEIRA, Bruno de Sousa. Assessoria Jurídica Universitária e Moradia: O Caso Vila Vicentina. Extensão em Ação, Fortaleza, v. 2, n.14, p.44-57, Jul/Dez. 2017.

OBSERVATÓRIO DAS METRÓPOLES. Comitê das ZEIS: em busca do Direito à Cidade. Disponível em:

$<$ http://observatoriodasmetropoles.net/index.php?option=com_k2\&view=item\&id=1425:comi t $\%$ C3\%AA-das-zeis-em-busca-do-direito-\%C3\%A0-cidade-em-

fortaleza\&Itemid=180\&lang=pt>. Acesso em: 01 set. 2018.

PEQUENO, Luis Renato Bezerra; FREITAS, Clarissa Figueiredo Sampaio. Desafios para implementação de Zonas Especiais de Interesse Social em Fortaleza. Rio de Janeiro: XIV Encontro Nacional da Anpur, 2011.

RICCI, Rudá. Associativismo paulistano e cultura ambivalente. In: AVRITZER, Leonardo (Org.). A participação em São Paulo. São Paulo: editora UNESP, 2002.

ROLNIK, Raquel; SANTORO, Paula Freire. Zonas Especiais de Interesse Social (ZEIS) em Cidades Brasileiras: Trajetória Recente de Implementação de um Instrumento de Política Fundiária. Lincoln Institute of Land Policy. 2014. Disponível em:

$<$ https://www.lincolninst.edu/publications/working-papers/zonas-especiais-interesse-socialzeis-em-cidades-brasileiras $>$. Acesso em: 01 set. 2018.

SANTOS, Milton. A urbanização brasileira. São Paulo: Hucitec, 1993

SILVA, Ana Amélia da. Reforma Urbana e o Direito à Cidade. São Paulo: PÓLIS, 1991.

SOUZA, M. L., Mudar a cidade, Rio de Janeiro: Bertrand Brasil, 2001.

VASCONCELOS, André Aghasi; GRADVOHL, Marina Brasil. Valores e Educação Popular na Assessoria Jurídica Universitária Popular. Extensão em Ação, Fortaleza, v. 1, n. 13, p.44- 53, Jan/Jun. 2017.

VIEIRA, Eriton Geraldo. O Direito à Cidade Sustentável no Estado Democrático de Direito. 2015. Dissertação (Mestrado em Direito). Programa de Pós- Graduação em DireitoEscola Superior Dom Helder Câmara. Belo Horizonte. 2015. Disponível em:

$<$ http://domhelder.edu.br/mestrado/editor/assets/arquivos_dissertacoesdefendidas/3575c267e9 e b00bbc7c94beb8421ef76.pdf>. Acesso em: 31 ago. 2018.

VILLAÇA, Flávio. Uma contribuição para a história do planejamento urbano no Brasil. In: DÉAK, Csaba; SCHIFFER, Sueli Ramos (orgs). O processo de urbanização no Brasil. São Paulo: Editora da Universidade de São Paulo, 1999, p. 169-243. 